\title{
GENERALISED DELETION DESIGNS
}

\author{
Michael Kamau Gachii and John Wycliff Odhiambo \\ * Department of Mathematics, University of Nairobi, P. O. Box 30197, Nairobi, Kenya
}

\begin{abstract}
In this paper asymmetrical single replicate factorial designs are constructed from symmetrical single replicate factorial designs using the deletion technique. The study is along the lines of Voss(1986), Chauhan(1989) and Gachii and Odhiambo(1997). We give results for the general order deletion designs of the form $\mathrm{s}^{\mathrm{n}-\mathrm{m}_{1}}(\mathrm{~s}-\mathrm{L})^{\mathrm{m}_{1}}$ which are proper, for $1 \leq \mathrm{L} \leq \mathrm{s}-1$ and $\mathrm{m}_{1}$ less than or equal to the number of generators of the preliminary single replicate generalized cyclic design. We generalize results by earlier authors. Results identifying the set of estimable factorial effects of the deletion designs based on the information available from the preliminary factorial design are given. Simple formulas for calculating the loss of information due to confounding with blocks are given. Efficiency with respect to the number of treatment combinations needed to estimate a given set of interactions of the preliminary factorial design is compared with that of the resulting deletion designs.
\end{abstract}

Key words and phrases: Factorial spaces, generalized cyclic designs, loss of information.

\section{INTRODUCTION}

To construct a single replicate factorial design having $\mathrm{n}$ factors $F_{1}, F_{2}, \ldots, F_{\mathrm{n}}$, factor $\mathrm{F}_{\mathrm{i}}$ occurring at $s_{\mathrm{i}}$ levels, we first construct a single replicate preliminary block design, say $d_{\mathrm{p}}$, in $\mathrm{n}$ factors, factor $F_{i}$ occurring at $r_{i}$ levels, using any of the known methods such that $r_{\mathrm{i}} \geq s_{\mathrm{i}}$ for $i=$ $1,2, \ldots$, n. We can then select $l_{\mathrm{i}}=r_{\mathrm{i}-} s_{\mathrm{i}}$ levels of the $i$-th factor of $d_{\mathrm{p}}$ and delete from $d_{\mathrm{p}}$ all treatment combinations where factor $F_{\mathrm{i}}$ occurs at any of the $l_{\mathrm{i}}$ selected levels. If levels are deleted from $k$ factors we refer to the resulting design as a $k$-th order deletion design.

Earlier work on this area was done by Bose (1947). He used finite Euclidean geometry to construct asymmetrical factorial designs in blocks. Kishen and Srivastava extended the method of finite geometries to the construction of balanced confounded asymmetrical factorial designs thereby introducing the idea of deletion.

John and Dean (1975) proposed a simple method of confounding based on generalized cyclic designs from a set of generating treatments or generators and showed that the confounding patterns could easily be determined from these generators.

Voss (1986) constructed nearly orthogonal singe replicate factorial designs in blocks. He uses the deletion technique, where he deletes from the first factor without loss of generality to obtain first order deletion designs. Chauhan (1989) generalized the work by Voss (1986), by constructing efficient single replicate designs using the deletion technique. Starting from an $\mathrm{s}^{\mathrm{n}}$ generalized cyclic design, she constructed efficient proper single replicate deletion designs of the form $(\mathrm{s}-\mathrm{L}) \mathrm{s}^{\mathrm{n}-1}$. Gachii and Odhiambo (1998) Constructed deletion designs of the form $\mathrm{s}^{\mathrm{n}-\mathrm{m}_{i}}(\mathrm{~s}-\mathrm{L})^{\mathrm{m}_{i}} \quad$ which are proper for $1 \leq \mathrm{L} \leq \mathrm{s}-1$ and $\mathrm{m}_{1}$ less than or equal to the number of generators of the preliminary single replicate generalized cyclic design. 
The objective of the present paper is to give general results useful in evaluating the efficiency of the constructed deletion designs based on the loss of information on the estimable effects.

To construct the preliminary single replicate factorial design in which factor $\mathrm{F}_{\mathrm{i}}$ occurs at $\mathrm{r}_{\mathrm{i}}=$ s levels for $i=$ $1,2, \ldots, n$ we use the method by John and Dean (1975). We derive expressions for loss of information due to deletion on the estimable effects. Confounding patterns on the deletion designs are also given.

\section{NOTATION}

We assume the fixed effects linear model

$$
\mathrm{y}_{\mathrm{ah}}=\mu+\tau_{\mathrm{a}}+\beta_{\mathrm{h}}+\varepsilon_{\mathrm{ah}}
$$

where $\mathrm{y}_{\mathrm{ah}}$ denotes the observed yield from treatment combination $\mathbf{a}$ in the $h$-th block; $\tau_{\mathrm{a}}$ denotes the effect of treatment combination $\boldsymbol{a} ; \beta_{\mathrm{h}}$ denotes the effect of the $h$ th block and $\varepsilon_{\mathrm{ah}}$ are uncorrelated random errors with zero mean and variance $\sigma^{2}$. Let $y=\left(y_{\text {ah }}\right)$ and $\tau=\tau_{\text {a }}$ denote the $v \mathrm{x} 1$ vectors of observations and treatment effects respectively each lexicographically ordered by $\mathbf{a}$. That is a treatment combination $a=a_{1} a_{2} \ldots a_{\mathrm{n}}$ appears before another treatment combination $\mathrm{a}^{*}=\mathrm{a}_{1}^{*} \mathrm{a}_{2}^{*} \ldots . \mathrm{a}_{\mathrm{n}}^{*}$ if and only if for the first $u$ such that $a_{u} \neq a_{u}^{*}$ we have $a_{u}<a_{u}^{*}$ for $1 \leq \mathrm{u} \leq \mathrm{n}$ The $i$-th row of $\mathbf{y}$ and $\tau$ above corresponds to the $i$-th treatment combination in the above arrangements of the $\mathrm{v}$ treatment combinations.

We shall denote the incidence matrix, the intra block matrix, the diagonal matrix of block sizes and the number of blocks respectively by N,A,K and b. The $i$-th row of the incidence matrix $\mathrm{N}$ corresponds to the $i$-th lexicographically ordered treatment combination a. the qx1 vectors of ones and of zeros will be denoted by $\underline{1}_{\mathrm{q}}$ and $\underline{0}_{q}$ respectively.

A generalized interaction will be denoted by $\alpha^{\mathrm{x}}$ where $\mathrm{x}=\mathrm{x}_{1} \mathrm{x}_{2} \ldots \mathrm{x}_{\mathrm{n}}$ such that $\mathrm{x}_{\mathrm{j}}=1$ if $\mathrm{F}_{\mathrm{j}}$ is present in the interaction and $\mathrm{x}_{\mathrm{j}}=0$ otherwise. A v $\mathrm{x} 1$ contrast vector will be denoted by $c^{\mathrm{x}}$ where

$$
\mathrm{c}^{\mathrm{x}}=\mathrm{c}_{1}^{\mathrm{x}_{1}} \otimes \mathrm{c}_{2}^{\mathrm{x}_{2}} \otimes \ldots . \otimes \mathrm{c}_{\mathrm{n}}^{\mathrm{x}_{\mathrm{n}}}
$$

with $\mathrm{c}_{\mathrm{j}}^{\mathrm{x}_{\mathrm{j}}}$ being an $\mathrm{S}_{\mathrm{j}} \mathrm{x} 1$ vector of ones if $\mathrm{x}_{\mathrm{j}}=0$, otherwise it is an $\mathrm{S}_{\mathrm{j}} \mathrm{x} 1$ contrast vector. The minimum variance unbiased estimator of the generalised interaction $\alpha^{\mathrm{x}}$ is represented by $\mathrm{p}$ while those corresponding to the deletion design will carry no subscript.

\section{LOSS OF INFORMATION ON ESTIMABLE EFFECTS}

We shall use the notation

$\mathrm{d}_{\mathrm{a}_{\mathrm{j}}}=\underline{1}_{(\mathrm{s}-1)}^{\prime} \mathrm{D}_{\mathrm{j}} \mathrm{p}^{\mathrm{a}_{\mathrm{j}}} \quad \mathrm{D}_{\mathrm{j}}^{\prime} \underline{1}_{(\mathrm{s}-1)}$

where $D_{\mathrm{j}}$ is the matrix obtained from an $s$ x $s$ identity matrix by deleting the $t$-th row if the $t$-th level is deleted from factor $F_{\mathrm{j}}$ in the preliminary design $d_{-\mathrm{p}}$ to obtain $d$ and $\mathrm{s}_{\mathrm{j}} \mathrm{Xs}$ is an $s \mathrm{x} s$ permutation matrix with 1 in the $a_{j}$ - th column of the $o$-th row.

We shall also write

$d_{a_{j}}^{*}=c_{j}^{\prime} D_{j} P^{a_{j}} D_{j}^{\prime} c_{j}$

where $c_{j}$ is a contrast vector from the column space of the matrix $\mathrm{SI}_{(\mathrm{s})}-\mathrm{J}_{(\mathrm{s})}$. Again where $\mathrm{I}_{(\mathrm{s})}$ is an $\mathrm{s}$ dimensional identity matrix and $\mathrm{J}_{(\mathrm{s})}=\underline{1}_{(\mathrm{s})} \underline{1}_{(\mathrm{s})}^{\prime}$.

Following Dean (1978), for a given contrast vector $\mathrm{c}^{\mathrm{x}}$, the loss of information $\psi_{x}, 0 \leq \psi_{x} \leq 1$, due to confounding with blocks, is given by

$\psi_{\mathrm{x}}=\frac{\mathrm{c}^{\mathrm{x}^{\prime}} \mathrm{N} \mathrm{K}^{-1} \mathrm{~N}^{\prime} \mathrm{c}^{\mathrm{x}}}{\mathrm{c}^{\mathrm{x}^{\prime}} \mathrm{c}^{\mathrm{x}}}$

Where $\mathrm{N}$ is the incidence matrix and $\mathrm{K}$ is the diagonal matrix of block sizes.

We consider deletion designs of the form $\mathrm{s}^{\mathrm{n}-\mathrm{m}_{i}}(\mathrm{~s}-1)^{\mathrm{m}_{i}}$ with $\mathrm{b}=\lambda \mathrm{s}^{\mathrm{n}-\mathrm{m}}$ blocks each of size $\mathrm{K}=(1 / \lambda) \mathrm{S}^{\mathrm{m}-\mathrm{m}_{i}}(\mathrm{~s}-1)^{\mathrm{m}_{i}}$ derived from an $S^{n}$ generalised cyclic design $d_{p}$ with $K_{p}=(1 / \lambda) S^{m}$ and $\mathrm{b}_{\mathrm{p}}=\lambda \mathrm{s}^{\mathrm{n}-\mathrm{m}}$. Where $n$ is the number of factors, $m$ is the number of generators, $m_{1}$ is the order of the deletion design and $\lambda=\prod_{i=1}^{m} 1 / b_{i}$ with $b_{i}=\operatorname{HCF}\left(s, g_{i}\right), \quad i=1,2, \ldots, m$ as given by John and Dean (1975). 
We now give general results on loss of information for a given interaction effect on these designs.

\section{Lemma 3.1:}

Loss of information due to confounding with blocks on any $r$-factor interaction of the form $\mathrm{F}_{\mathrm{i}_{1}} \mathrm{~F}_{\mathrm{i}_{2}} \ldots . \mathrm{F}_{\mathrm{ir}}$, $\left\{i_{1}, i_{2}, \ldots, i_{r}\right\} \subset\left\{1,2, \ldots ., n-m_{1}\right\}$ whose levels were not deleted for all the factors in the interaction to obtain $\mathrm{d}$ is given by

$$
\psi_{\mathrm{x}}=\frac{\lambda \sum_{\mathrm{a}_{1}} \sum_{\mathrm{a}_{2}} \ldots . \sum_{\mathrm{a}_{\mathrm{n}}} \mathrm{w}_{\mathrm{a}_{1} \mathrm{a}_{2} \ldots \mathrm{a}_{\mathrm{n}}} \mathrm{d}_{\mathrm{a}_{\mathrm{a}_{1}} \mathrm{a}_{2} \ldots \mathrm{a}_{\mathrm{n}}} \mathrm{d}_{\mathrm{a}_{\mathrm{in}}}^{*} \mathrm{~d}_{\mathrm{a}_{\mathrm{i}}}^{*} \ldots . . \mathrm{d}_{\mathrm{a}_{\mathrm{ir}}}^{*}}{(\mathrm{~s}-1)^{\mathrm{r}}(\mathrm{s}-1)^{2 \mathrm{~m}_{1}} \mathrm{~s}^{\mathrm{n}+\mathrm{m}-2 \mathrm{~m}_{1}}}
$$

where

$\mathrm{w}_{\mathrm{a}_{1} \mathrm{a}_{2} \ldots \mathrm{a}_{\mathrm{n}}}=\left\{\begin{array}{l}1, \text { if } \mathrm{a}=\mathrm{a}_{1} \mathrm{a}_{2} \ldots \mathrm{a}_{\mathrm{n}} \text { is in the initial block of } \mathrm{d}_{\mathrm{p}} \\ 0, \text { otherwise }\end{array}\right.$

again where $d_{a_{1} a_{n}}=d_{a_{1}} \times d_{a_{2}} \times \ldots . . \times d_{a_{n}}$ is such that it does not contain $d_{a_{i}}, d_{a_{i}}, d_{a_{i}}$ since for these factors we have instead $d_{a_{i j}}^{*}, d_{a_{i n}}^{*}, \ldots . ., d_{a_{i,}}^{*}$ which are contrast vectors from $\mathrm{SI}_{(\mathrm{s})}-\mathrm{J}_{(\mathrm{s})}:$

Proof: The contrast vector $\mathrm{c}^{\mathrm{x}}$ is as given in (2.2) with $\mathrm{c}_{\mathrm{t}}^{\mathrm{x}_{t}}$ being an sx1 unit vector for is an $(\mathrm{s}-l) \mathrm{x} 1$ unit vector for $t \pm i_{1}, i_{2}, \ldots i_{r}, t=1,2, \ldots, n-m_{1}, c_{t}^{x_{t}}$ is any of the columns of the matrix $s I_{(s)}-J_{(s)}$ for $t=i_{1}, i_{2}, \ldots i_{r}$. Therefore

$\mathrm{c}^{\mathrm{x}^{\prime}} \mathrm{c}^{\mathrm{x}}=(\mathrm{s}-1)^{\mathrm{r}}(\mathrm{s}-1)^{\mathrm{m}_{1}} \mathrm{~s}^{\mathrm{n}-\mathrm{m}_{1}}$

But

$\mathrm{K}^{-1}=\left(\lambda \backslash \mathrm{s}^{\mathrm{m}-\mathrm{m}_{\mathrm{t}}}(\mathrm{s}-1)^{\mathrm{m}_{\mathrm{t}}}\right) \mathrm{I}_{\left(\lambda \lambda^{--}\right)}$

and

$\mathrm{c}^{\mathrm{x}^{\prime}} \mathrm{NN}^{\prime} \mathrm{c}^{\mathrm{x}}=\sum_{\mathrm{a}_{1}} \sum_{\mathrm{a}_{2}} \ldots \ldots \sum_{\mathrm{a}_{\mathrm{s}}} \mathrm{w}_{\mathrm{a}_{1}} \ldots . \mathrm{a}_{\mathrm{n}} \mathrm{d}_{\mathrm{a}_{1} \mathrm{a}_{2} \ldots \mathrm{a}_{\mathrm{n}}} \mathrm{d}_{\mathrm{a}_{\mathrm{i}_{i 1}}}^{*} \mathrm{~d}_{\mathrm{a}_{\mathrm{i}_{2}}}^{*} \ldots \mathrm{d}_{\mathrm{a}_{\mathrm{i}}}^{*}$

using (3.1) and (3.2).

Hence using (3.4),(3.5) and (3.6) we obtain Lemma 3.1.

Lemma 3.2: Loss of information due to confounding with blocks on any $r$-factor interaction of the form $\mathrm{F}_{\mathrm{i},}, \mathrm{F}_{\mathrm{i},} \ldots . \mathrm{F}_{\mathrm{ir}},\left\{\mathrm{i}_{1}, \mathrm{i}_{2}, \ldots ., \mathrm{i}_{\mathrm{r}}\right\} \subset\left\{1,2, \ldots . ., \mathrm{n}-\mathrm{m}_{1}\right\}$ whose levels were not deleted and $\left\{i_{r+1}, i_{r_{1,2}}, \ldots, i_{r}\right\} \subset\left\{\mathrm{n}-\mathrm{m}_{1}+1, \mathrm{n}-\mathrm{m}_{1}+2, \ldots ., \mathrm{n}\right\}$ whose levels were deleted to obtain $\mathrm{d}$ is given by

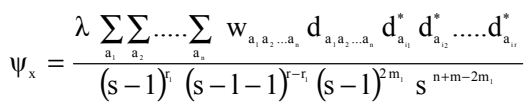

where $\mathrm{w}_{\mathrm{a}_{\llcorner} \mathrm{a}_{\mathrm{n}}}$ and $\mathrm{d}_{\mathrm{a}_{\llcorner} \mathrm{a}_{\mathrm{n}}}$ is as given in lemma 3.1 and $\mathrm{d}_{\mathrm{a}_{\mathrm{i}_{1}}}^{*}, \mathrm{~d}_{\mathrm{a}_{\mathrm{i}_{2}}}^{*}, \ldots . ., \mathrm{d}_{\mathrm{a}_{\mathrm{i}^{i}}}^{*}$ are contrast vectors from $\mathrm{SI}_{(\mathrm{s})}-\mathrm{J}_{(\mathrm{s})}$ and $\mathrm{d}_{\mathrm{a}_{\mathrm{in}_{1}+1}}^{*}, \ldots . ., \mathrm{d}_{\mathrm{a}_{\mathrm{i}}}^{*}$ are contrast vectors from $(\mathrm{S}-1) \mathrm{I}_{(\mathrm{s}-1)}-\mathrm{J}_{(\mathrm{s}-1)}$.

Proof: The contrast vector $c^{\mathrm{x}}$ is as given in (2.2) with $\mathrm{c}_{\mathrm{t}}^{\mathrm{x}_{\mathrm{t}}}$ being an sx1 unit vector for is an $(\mathrm{s}-l) \mathrm{x} 1$ unit vector for $\mathrm{t}=\mathrm{n}-\mathrm{m}_{1}+1, \mathrm{n}-\mathrm{m}_{1}+2, \ldots, \mathrm{n}$ and $\mathrm{t} \pm \mathrm{i}_{1}, \mathrm{i}_{2}, \ldots, \mathrm{i}_{\mathrm{r}}$ and $\mathrm{c}_{\mathrm{t}}^{\mathrm{x}}$

Is any of the columns of the matrix $s I_{(s)}-J_{(s)}$ for $t=i_{1}, i_{2}, \ldots i_{r_{1}}, i_{j} \leq n-m_{1}, j=1,2, . ., r_{1}$ and $c_{t}^{x_{t}}$ is any of the columns of the matrix $(s-1) \mathrm{I}_{(\mathrm{s}-1)}-\mathrm{J}_{(\mathrm{s}-1)}$ for $\left.\mathrm{t}=\mathrm{i}_{\mathrm{r}_{1}+1}, \mathrm{i}_{\mathrm{r}_{1}+2}, \ldots, \mathrm{i}_{\mathrm{r}}, \mathrm{i}_{\mathrm{j}}\right\rangle \mathrm{n}-\mathrm{m}_{1}, \mathrm{j}=\mathrm{r}_{1}+1, . . \mathrm{r}$ Therefore $\mathrm{c}^{\mathrm{x}^{\prime}} \mathrm{c}^{\mathrm{x}}=(\mathrm{s}-1)^{\mathrm{r}_{1}}(\mathrm{~s}-1-1)^{\mathrm{r}-\mathrm{r}_{\mathrm{i}}}(\mathrm{s}-1)^{\mathrm{m}_{1}} \mathrm{~s}^{\mathrm{n}-\mathrm{m}_{1}}$

Hence using (3.5),(3.6) and (3.7) we obtain Lemm 3.2

\section{Lemma 3.3}

Loss of information due to confounding with blocks on any $r$-factor interaction of form $F_{i}, F_{i}, \ldots . F_{i r}$ for which levels of all the factors were deleted from $d_{p}$ to obtain $d$ is given by

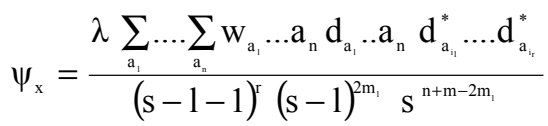

where $\mathrm{w}_{\mathrm{a}_{1} \mathrm{a}_{\mathrm{n}}}$ and $\mathrm{d}_{\mathrm{a}_{\mathrm{a}_{\mathrm{a}}} \mathrm{a}_{\mathrm{a}}}$ is as given in lemma 3.1 and $\mathrm{d}_{\mathrm{a}_{\mathrm{it}+1}}^{*}, \ldots . ., \mathrm{d}_{\mathrm{a}_{\mathrm{i}+}}^{*}$ are contrast vectors from $(\mathrm{S}-1) \mathrm{I}_{(\mathrm{s}-1)}-\mathrm{J}_{(\mathrm{s}-1)}$.

Proof: The contrast vector $\mathrm{c}^{\mathrm{x}}$ is as given in (2.2) with $\mathrm{c}_{\mathrm{t}}^{\mathrm{x}_{\mathrm{t}}}$ being an sx 1 unit vector for $\mathrm{t}=1,2, \ldots, \mathrm{n}-\mathrm{m}_{1}, \mathrm{c}_{\mathrm{t}}^{\mathrm{x}_{\mathrm{t}}}$ is an $(\mathrm{s}-l) \mathrm{x} 1$ unit vector for $\mathrm{t}=\mathrm{n}-\mathrm{m}_{1}+1, \mathrm{n}-\mathrm{m}_{1}+2, \ldots, \mathrm{n}$ and $\mathrm{t} \pm \mathrm{i}_{1}, \mathrm{i}_{2}, \ldots, \mathrm{i}_{\mathrm{r}}$ and $\mathrm{c}_{\mathrm{t}}^{\mathrm{x}_{\mathrm{v}}}$

Is any of the columns of the matrix $(s-1) I_{(s-1)}-J_{(s-1)}$ for $\mathrm{t}=\mathrm{i}_{1}, \mathrm{i}_{2}, \ldots \mathrm{i}_{\mathrm{r}}$. Hence

$c^{x^{\prime}} c^{x}=(s-1-1)^{r}(s-1)^{m_{i}} s^{n-m_{1}}$

Hence using (3.5),(3.6) and (3.8) we obtain Lemma 3.3 


\section{CONFOUNDING IN DELETION DESIGNS}

The following results in confounding in generalised cyclic designs is due to John and Dean (1975). The number of degrees of freedom confounded with blocks for any given interaction $\alpha^{\mathrm{x}}$ is given by

$\mathrm{Y}^{\mathrm{x}}=1 / \mathrm{k} \sum_{\mathrm{a}_{1}} \sum_{\mathrm{a}_{2}} \ldots . . \sum_{\mathrm{a}_{\mathrm{n}}} \mathrm{w}_{\mathrm{a}_{1}} \ldots . \mathrm{a}_{\mathrm{n}}\left(\prod_{\mathrm{j}=1}^{\mathrm{n}} \mathrm{z}_{\mathrm{a}_{\mathrm{j}}}^{\mathrm{x}_{\mathrm{j}}}\right)$

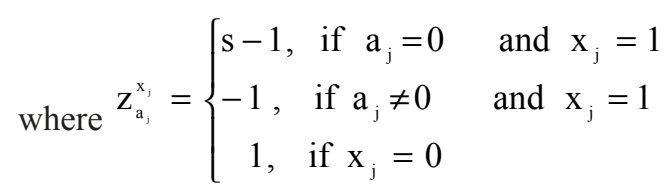

and $\mathrm{w}_{\mathrm{a}_{1} \mathrm{a}_{\mathrm{n}}}$ is as given in Lemma 3.1.

If the number of degrees of freedom in (4.1) is zero, then the interaction is unconfounded with blocks and if it is $\prod_{j=1}^{n}(s-1)^{x_{j}}$ the interaction is totally confounded with blocks. Consider any interactions between the $\mathrm{n}$ factors, say the interactions of the factors $F_{i_{1}}, F_{i_{2}} \ldots . F_{i r}$

Let

$A=\left(\left(a_{i j}\right)\right)$

where $\mathrm{a}_{\mathrm{ij}}$ is from the $i$-th generator $\mathrm{g}_{1}=\mathrm{a}_{\mathrm{i}_{1}} \mathrm{a}_{\mathrm{i}_{2}} \ldots . . \mathrm{a}$; $\mathrm{i}=1,2 \ldots . \mathrm{m}$ and $\mathrm{j}=\mathrm{i}_{1}, \mathrm{i}_{2}, \ldots, \mathrm{i}_{\mathrm{r}}$.

Consider all the $f \mathrm{x} f$ submatrices contained in the $j_{1}$-th, $j_{2}$-th, ........ $\mathrm{j}_{\mathrm{r}}$-th rows of $A$ and let $\mathrm{h}_{\mathrm{j}_{1} \ldots . . \mathrm{j}_{\mathrm{s}}}$ be the absolute values of their determinants $(\mathrm{f} \leq \mathrm{r}, \mathrm{f} \leq \mathrm{m})$. Define as follows

$\mathrm{H}_{\mathrm{f}}=\left\{\begin{array}{l}1, \text { if } \mathrm{f}=0 \\ \operatorname{HCF}\left(\mathrm{h}_{\mathrm{j}_{1}, \mathrm{j}_{2}, \ldots, \mathrm{j}_{\mathrm{r}}} \backslash\left\{\mathrm{j}_{1}, \mathrm{j}_{2}, \ldots, \mathrm{j}_{\mathrm{f}}\right\} \subset\left\{\mathrm{i}_{1}, \mathrm{i}_{2}, \ldots \mathrm{i}_{\mathrm{r}}\right\}\right) \text { if } 0<\mathrm{f}<\mathrm{m} \\ 0, \text { if } \mathrm{f}>\mathrm{m}\end{array}\right.$

In our case the treatment combinations in the initial block are of the form

$u_{1} g_{1}+u_{2} g_{2}+\ldots+u_{m} g_{m}\left(u_{i}=0,1, \ldots . . k_{i}-1 ; i=1,2, \ldots . m\right)$

The number of treatments in the initial block with $i_{1}$-th, $i_{2}$-th, $\ldots, i_{\mathrm{r}}$-th factors all zero is given by $\mathrm{s}{ }^{\mathrm{m}-\mathrm{r}} \mathrm{W}_{\mathrm{i}_{1}, \ldots \mathrm{i}_{+}}$where $\mathrm{w}_{\mathrm{i}_{1}, \ldots, \mathrm{i}_{e}}=\left\{\begin{array}{c}\prod_{\mathrm{r}=1}^{\mathrm{r}} \operatorname{HCF}\left(\mathrm{s}, \mathrm{H}_{\mathrm{f}} / \mathrm{H}_{\mathrm{f}-1}\right), \text { if } \mathrm{r} \leq \mathrm{m} \text { and } \mathrm{H}_{\mathrm{r}} \neq 0 \\ \mathrm{~s}^{\mathrm{r}-\mathrm{g}} \operatorname{HCF}\left(\mathrm{w}_{\mathrm{j}_{1}, \ldots, \mathrm{j}_{\mathrm{g}}} \backslash\left\{\mathrm{j}_{1}, \mathrm{j}_{2}, \ldots, \mathrm{j}_{\mathrm{g}}\right\} \subset\left\{\mathrm{i}_{1}, \mathrm{i}_{2}, \ldots, \mathrm{i}_{\mathrm{r}}\right\} \text { if } \mathrm{g}<\mathrm{r} \leq \mathrm{m}\right. \\ \mathrm{s}^{\mathrm{r}-\mathrm{g}} \operatorname{HCF}\left(\mathrm{w}_{\mathrm{j}_{1} \mathrm{j}_{2}, \ldots \mathrm{j}_{\mathrm{m}}} \backslash\left\{\mathrm{j}_{1}, \mathrm{j}_{2}, \ldots, \mathrm{j}_{\mathrm{m}}\right\} \subset\left\{\mathrm{i}_{1}, \mathrm{i}_{2}, \ldots, \mathrm{i}_{\mathrm{r}}\right\} \text { if } \mathrm{r}>\mathrm{m}\right. \\ .\end{array}\right.$

where $g$ is such that $\mathrm{H}_{\mathrm{g}} \neq 0$ and $\mathrm{H}_{\mathrm{g}+1}=\mathrm{H}_{\mathrm{g}+2}=. .=0$ and $g=1$ if $H_{1}=0$. Let $Y^{x}$ be denoted by $\mathrm{Y}_{\mathrm{j}_{1} \mathrm{j}_{2} \ldots \mathrm{j}_{n}}$ where $\mathrm{x}$ has the $j_{1}$-th, $\mathrm{j}_{2}$-th, $\ldots . ., j_{h}$-th digits unity and the remainder zero. Then it can be shown that for the interactions of the factors $\mathrm{F}_{\mathrm{i}_{1}}, \mathrm{~F}_{\mathrm{i}_{2}} \ldots . \mathrm{F}_{\mathrm{i}_{\mathrm{r}}}$, the number of degrees of freedom confounded with blocks is given by

$\mathrm{Y}_{\mathrm{i}_{1}, \ldots, \mathrm{i}}=\mathrm{W}_{\mathrm{i}_{1} \mathrm{i}_{2} \ldots \mathrm{i}_{\mathrm{r}}}-\sum_{\mathrm{g}=1}^{\mathrm{r}-1}\left(\mathrm{Y}_{\mathrm{j}_{1}, \ldots, \mathrm{j}} \backslash\left\{\mathrm{j}_{1}, \mathrm{j}_{2}, \ldots \mathrm{j}_{\mathrm{g}}\right\} \subset\left\{\mathrm{i}_{1}, \mathrm{i}_{2}, \ldots \mathrm{j}_{\mathrm{r}}\right\}\right)-1$

We now give the following results on confounding in deletion designs.

Chauhan (1989) studied confounding in deletion designs and the following discussion and theorem 1 below is due to her. Let $\alpha^{x}$ be a given interaction. Then the factors $\mathrm{F}_{\mathrm{i}_{1}}, \mathrm{~F}_{\mathrm{i}_{2}} \ldots . \mathrm{F}_{\mathrm{ir}}$ or simply $\{1,2, \ldots . ., \mathrm{n}\}$ can be partitioned into three mutually exclusive and exhaustive sets $\Omega_{1}, \Omega_{2}$, and $\Omega_{3}$ as follows: $\Omega_{1}$ contains the factors whose levels were not deleted from $d_{p}$ to obtain $d$, that is the factors $\left\{1,2, \ldots . ., \mathrm{n}-\mathrm{m}_{1}\right\} ; \Omega_{2}$ contains the factors whose levels were deleted from $d_{p}$ to obtain $d$ and these factors are not in the factorial space $\mathrm{V}_{\mathrm{x}}$, that is the factors $\left\{\mathrm{n}-\mathrm{m}_{1}+1, \mathrm{n}-\mathrm{m}_{1}+2, \ldots ., \mathrm{n}-\mathrm{m}_{1}+\mathrm{a}\right\} ; \Omega_{3}$ contains the factors whose levels were deleted from $d_{p}$ to obtain $\mathrm{d}$ and these factors are in the factorial space $\mathrm{V}_{\mathrm{x}}$, that is the factors $\left\{n-m_{1}+a+1, n-m_{1}+a+2, \ldots, n\right\}$; $\mathrm{a}=0,1,2, \ldots, \mathrm{m}_{1}$.

We shall write the factorial space $\mathrm{V}_{\mathrm{x}}$ as $\mathrm{V}\left(\mathrm{j}_{1}, \mathrm{j}_{2}, \ldots, \mathrm{j}_{\mathrm{r}}\right)$ if $\mathrm{x}_{\mathrm{j}}=\mathrm{x}_{\mathrm{j}_{\mathrm{r}}}=\ldots=\mathrm{x}_{\mathrm{j}_{\mathrm{r}}}=1$ and all other $\mathrm{x}_{\mathrm{j}}{ }^{\prime} \mathrm{s}$ are zero, where $\left\{i_{1}, i_{2}, \ldots ., i_{r}\right\} \subset\left\{1,2, \ldots ., n-m_{1}\right\}$, then we have the following theorem. 


\section{Theorem 1: (Chauhan (1989))}

Let the contrast vector

$\mathrm{c}^{\mathrm{x}} \in \mathrm{v}\left(\mathrm{i}_{1}, \mathrm{i}_{2}, \ldots ., \mathrm{i}_{\mathrm{r}}, \mathrm{n}-\mathrm{m}_{1}+\mathrm{a}+1, \mathrm{n}-\mathrm{m}_{1}+\mathrm{a}+2, \ldots ., \mathrm{n}\right)$

and let $\mathrm{c}_{\mathrm{p}}^{\mathrm{x}}=\mathrm{D}^{\prime} \mathrm{c}^{\mathrm{x}}$

then

$\mathrm{c}_{\mathrm{p}}^{\mathrm{x}} \in \oplus \mathrm{v}_{\mathrm{p}}\left(\mathrm{i}_{1}, \mathrm{i}_{2}, \ldots, \mathrm{i}_{\mathrm{r}}, \mathrm{g}, \mathrm{n}-\mathrm{m}_{1}+\mathrm{a}+1, \mathrm{n}-\mathrm{m}_{1}+\mathrm{a}+2, \ldots ., \mathrm{n}\right)$

where $g \in \mathrm{p}\left(\Omega_{2}\right)$; that is $\mathrm{g}$ belongs to the power set of

$\Omega_{2}$ and $\oplus$ denotes the direct sum. Where

$\mathrm{D}=\mathrm{D}_{1} \otimes \mathrm{D}_{2} \otimes \ldots . \mathrm{D}_{\mathrm{n}}$

again $\mathrm{D}_{\mathrm{j}}$ where is as defined in section 3 .

The following results on deletion designs follow:

\section{Theorem 2}

If $\mathrm{S}^{\mathrm{n}}$ is a generalised cyclic design generated by $m$ generators such that $\mathrm{g}_{1}=$ twice the $(n-m+1)$-th row of an identity matrix of order $n$ and $g_{2}, g_{3}, \ldots . ., g_{m}$ are the last (m-1) rows of an identity matrix of order $n$ and if $\mathrm{s}>2$ is even then all the main effects and all the interactions of the first $(n-m)$ factors are totally confounded with blocks while the main effect of factor $\mathrm{F}_{\mathrm{n}-\mathrm{m}+1}$ and any effects involving this factor and any number of the first $(n-m)$ factors are partially confounded with blocks provided $n \geq 2 \mathrm{~m}-1$.

Proof: For the main effects and interactions of the first factors, we have for the main effect of factor $\mathrm{F}_{\mathrm{j},}, \quad \mathrm{j}_{1}=1,2, \ldots ., \mathrm{n}-\mathrm{m}, \quad \mathrm{h}_{\mathrm{j}_{\mathrm{\iota}}}=\operatorname{HCF}(0,0, \ldots . ., 0)=0$, which gives

$\mathrm{w}_{\mathrm{j}_{1}}=\operatorname{HCF}(\mathrm{s}, 0)=\mathrm{s}$

and hence $\mathrm{Y}_{\mathrm{j}_{1}}=\mathrm{s}-1 \neq 0$ since $\mathrm{s}>1$.

Therefore all the main effects of the first $(n-m)$ factors are totally confounded with blocks using (4.5).

For two factors interactions of factors $F_{j_{1}}$ and $F_{j_{2}}$, $\mathrm{j}_{1}<\mathrm{j}_{2}=1,2, \ldots, \mathrm{n}-\mathrm{m}$, the matrix $\mathrm{A}$ in (4.2) is the zero matrix which gives $\mathrm{H}_{2}=0$. Therefore $\mathrm{w}_{\mathrm{j}_{1} \mathrm{j}_{2}}=\mathrm{s}^{2-1} \operatorname{HCF}(\mathrm{s}, \mathrm{s})=\mathrm{s}^{2}$

and so $\begin{aligned} \mathrm{Y}_{\mathrm{j}_{\mathrm{j}} \mathrm{j}_{2}} & =\mathrm{s}^{2}-2(\mathrm{~s}-1)-1 \\ & =(\mathrm{s}-1)^{2} \neq 0\end{aligned}$

since $s>1$. Hence by (4.5) all the two factors interactions of this form are totally confounded with blocks.

To obtain the result for the general case we proceed by induction. Assume the k-factor interactions are totally confounded with blocks for $\mathrm{k}=1,2, \ldots . ., \mathrm{n}-\mathrm{m}-1$, that is

$\mathrm{Y}_{\mathrm{j}_{1} \mathrm{j}_{2} \ldots \ldots \mathrm{j}_{\mathrm{k}}}=(\mathrm{s}-1)^{\mathrm{k}} \neq 0$

We wish to show that the $(\mathrm{k}+1)$ - factor interactions are totally confounded with blocks. From (4.5)

$\mathrm{Y}_{\mathrm{j}_{1} \mathrm{j}_{2} \ldots \ldots \mathrm{j}_{\mathrm{k}} \mathrm{j}_{\mathrm{k}+1}}=\mathrm{s}^{\mathrm{k}+1}-\sum_{\mathrm{g}=1}^{\mathrm{k}}\left(\mathrm{Y}_{\mathrm{i}_{1} \ldots \mathrm{i}_{\mathrm{s}}} \backslash\left\{\mathrm{i}_{1}, \mathrm{i}_{2}, \ldots, \mathrm{i}_{\mathrm{g}}\right\} \mathrm{C}\left\{\mathrm{j}_{1}, \mathrm{j}_{2}, . . \mathrm{j}_{\mathrm{k}} \mathrm{j}_{\mathrm{k}+1}\right\}\right)-1$

$=\mathrm{s}^{\mathrm{k}+1}-\left(\begin{array}{r}\mathrm{k}+1 \\ \mathrm{k}\end{array}\right) \mathrm{Y}_{\mathrm{j}_{\mathrm{i}} \mathrm{j}_{2} \ldots \mathrm{i}}-\left(\begin{array}{c}\mathrm{k}+1 \\ \mathrm{k}-1\end{array}\right) \mathrm{Y}_{\mathrm{j}_{\mathrm{i}} \mathrm{j}_{2} \ldots \mathrm{i}_{-1}}-\left(\begin{array}{c}\mathrm{k}+1 \\ 1\end{array}\right) \mathrm{Y}_{\mathrm{j}_{\mathrm{i}}}-\left(\begin{array}{c}\mathrm{k}+1 \\ 0\end{array}\right)$

$=\left(\begin{array}{c}\mathrm{k}+1 \\ \mathrm{k}+1\end{array}\right) \mathrm{s}^{\mathrm{k}+1}-\left(\begin{array}{c}\mathrm{k}+1 \\ \mathrm{k}\end{array}\right)(\mathrm{s}-1)^{\mathrm{k}}-\left(\begin{array}{c}\mathrm{k}+1 \\ \mathrm{k}-1\end{array}\right)(\mathrm{s}-1)^{\mathrm{k}-1}-\left(\begin{array}{c}\mathrm{k}+1 \\ 1\end{array}\right)(\mathrm{s}-1)-\left(\begin{array}{c}\mathrm{k}+1 \\ 0\end{array}\right)=(\mathrm{s}-1)^{\mathrm{k}+1}$

therefore all the $\mathrm{k}$-factor interactions, $\mathrm{k}=1,2, \ldots, \mathrm{n}-\mathrm{m}-1$ are totally confounded with blocks.

For the main effect of factor $\mathrm{F}_{\mathrm{n}-\mathrm{m}+1}$ we have

$\mathrm{h}_{\mathrm{n}-\mathrm{m}+1}=\operatorname{HCF}(0,0, \ldots, 0,2,0, \ldots, 0)=2$

Thus

$\mathrm{w}_{\mathrm{n}-\mathrm{m}+1}=\operatorname{HCF}(\mathrm{s}, 2)=2$

and therefore

$\mathrm{Y}_{\mathrm{n}-\mathrm{m}+1}=2-1=1<(\mathrm{s}-1)$

Hence one degree of freedom from the main effect of factor $F_{n-m+1}$ is confounded with blocks. Therefore the main effect of factor $F_{n-m+1}$ is partially confounded.

For the two factor interactions of the form $\mathrm{F}_{\mathrm{j}} \mathrm{F}_{\mathrm{n}-\mathrm{m}+1}, \quad \mathrm{j}_{1}=1,2, \ldots ., \mathrm{n}-\mathrm{m}$, the matrix $\mathrm{A}$ is of the form 


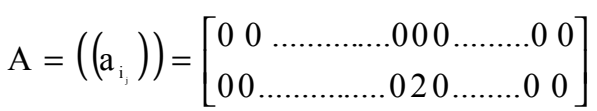

Hence $\mathrm{H}_{2}=0$. and

$\mathrm{w}_{\mathrm{j}_{\mathrm{l}} \quad \mathrm{n}-\mathrm{m}+1}=\mathrm{s}^{2-1} \operatorname{HCF}(\mathrm{s}, 2)=2 \mathrm{~s}$

Therefore

$$
\begin{aligned}
Y_{j_{1} \quad n-m+1} & =2 s-(s-1)-1-1 \\
& =s-1<(s-1)^{2}
\end{aligned}
$$

and it follows that the two factor interactions of this form are partially confounded with blocks.

In general for the $k$-factor interaction $\quad \mathrm{F}_{\mathrm{j}_{1}} \mathrm{~F}_{\mathrm{j}_{2}} \ldots \mathrm{F}_{\mathrm{j}_{\mathrm{k}-1}} \mathrm{~F}_{\mathrm{n}-\mathrm{m}+1}$ for $\mathrm{j}_{1}<\mathrm{j}_{2}<\ldots<\mathrm{j}_{\mathrm{k}-1}=1,2, \ldots \mathrm{n}-\mathrm{m}$, we get

$\mathrm{W}_{\mathrm{j}_{1} \mathrm{j}_{2} \ldots \mathrm{j}_{\mathrm{j}-1} \mathrm{n}-\mathrm{m+1}}=2 \mathrm{~s}^{\mathrm{k}-1}$

Therefore using (4.5)

$\mathrm{Y}_{\mathrm{i}, \mathrm{j}, \ldots, \mathrm{j} n \mathrm{n}+\mathrm{H}}=2 \mathrm{~s}^{\mathrm{k}-1}-\left[\left(\begin{array}{l}\mathrm{k} \\ \mathrm{k}-1\end{array}\right)-\left(\begin{array}{l}\mathrm{k}-1 \\ \mathrm{k}-1\end{array}\right)\right](\mathrm{s}-1)^{\mathrm{k}-2}-\left[\left(\begin{array}{l}\mathrm{k} \\ \mathrm{k}-2\end{array}\right)-\left(\begin{array}{l}\mathrm{k}-1 \\ \mathrm{k}-2\end{array}\right)\right](\mathrm{s}-1)^{\mathrm{k}-3}-\ldots$ $-\left[\left(\begin{array}{l}\mathrm{k} \\ 1\end{array}\right)-\left(\begin{array}{c}\mathrm{k}-1 \\ 1\end{array}\right)\right](\mathrm{s}-1)^{0}=(\mathrm{s}-1)^{\mathrm{k}-1}<(\mathrm{s}-1)^{\mathrm{k}}$

hence all interactions involving factor $F_{n-m+1}$ and any number of the first $(n-m)$ factors are partially confounded with blocks.

It can be shown that the $2 \mathrm{~s}^{\mathrm{n}-\mathrm{m}}-1$ degrees of freedom confounded with blocks are from the main effects and interactions of the first $(n-m)$ factors and from the main effect of factor and all the interactions involving factor $\mathrm{F}_{\mathrm{n}-\mathrm{m}+1}$ and any number of the first $(\mathrm{n}-\mathrm{m})$ factors provided $\mathrm{n} \leq 2 \mathrm{~m}-1$. Again the loss of information on the main effect of factor $\mathrm{F}_{\mathrm{n}-\mathrm{m}+1}$ or any two factor interactions of the form $F_{j} F_{n-m+1}, j=1,2, \ldots ., n-m$ due to confounding with blocks, is given by $\psi_{\mathrm{x}}=1 /(\mathrm{s}-1)$. The following results are on the efficiency of the class of deletion designs derived from the generalised cyclic designs above with respect to estimable effects.

Theorem 3: The main effect of factor $F_{n-m+1}$ and all the interactions involving this factor and any number of the first $(n-m)$ factors are partially confounded in these deletion designs.

Proof: In this case $\mathrm{c}^{\mathrm{x}} \in \mathrm{V}\left(\mathrm{i}_{1}, \mathrm{i}_{2}, \ldots ., \mathrm{i}_{\mathrm{e}}, \mathrm{n}-\mathrm{m}+1\right)$ where $\quad\left\{\mathrm{i}_{1}, \mathrm{i}_{2}, \ldots ., \mathrm{i}_{\mathrm{e}}\right\} \subset\{1,2, \ldots ., \mathrm{n}-\mathrm{m}\} \quad$ for $\mathrm{e}=1,2, \ldots ., \mathrm{n}-\mathrm{m}$. Hence $\Omega_{1}=\left\{\mathrm{i}_{1}, \mathrm{i}_{2}, \ldots ., \mathrm{i}_{\mathrm{e}}\right\}, \Omega_{2}=$ $\left\{\mathrm{n}-\mathrm{m}_{1}+1, \mathrm{n}-\mathrm{m}_{1}+2, \ldots ., \mathrm{n}\right\} \quad$ and $\Omega_{3}=\{\varphi\}$. Terefore the power set $\Omega_{2}$ is given by $\mathrm{P}\left(\Omega_{2}\right)=\{\varphi$,$\} ,$ $\left.\left\{\mathrm{n}-\mathrm{m}_{1}+1\right\},\right\} \ldots,\{\mathrm{n}\},\left\{\mathrm{n}-\mathrm{m}_{1}+1, \mathrm{n}-\mathrm{m}_{1}+2\right\}, \ldots .$, $\left.\left\{\mathrm{n}-\mathrm{m}_{1}+1, \mathrm{n}-\mathrm{m}_{1}+2, \ldots ., \mathrm{n}\right\}\right\}$

it follows from theorem 1 that if

$c_{p}^{x}=D^{\prime} c^{x}$

then

$\mathrm{c}_{\mathrm{p}}^{\mathrm{x}} \in \mathrm{V}_{\mathrm{p}}\left(\mathrm{i}_{1}, \mathrm{i}_{2}, \ldots, \mathrm{i}_{\mathrm{e}}, \mathrm{n}-\mathrm{m}+1\right) \oplus \mathrm{V}_{\mathrm{p}}\left(\mathrm{i}_{1}, \mathrm{i}_{2}, . ., \mathrm{i}_{\mathrm{e}}, \mathrm{n}-\mathrm{m}+1, \mathrm{n}-\mathrm{m}_{1}+1\right) \oplus$ $\ldots \oplus \mathrm{V}_{\mathrm{p}}\left(\mathrm{i}_{1}, \mathrm{i}_{2}, . . \mathrm{i}_{\mathrm{e}}, \mathrm{n}\right) \oplus \ldots \oplus \mathrm{V}_{\mathrm{p}}\left(\mathrm{i}_{1}, \mathrm{i}_{2}, \ldots, \mathrm{i}_{\mathrm{e}}, \mathrm{n}-\mathrm{m}+1, \mathrm{n}-\mathrm{m}_{1}+1, . ., \mathrm{n}\right)$

But all these factorial spaces are partially confounded in $\mathrm{d}_{\mathrm{p}}$ and hence the result.

Using a similar argument it can be shown that all the other main effects and interactions are fully estimable in these designs.

These deletion designs are derived from an generalised $\mathrm{S}^{\mathrm{n}}$ cyclic design generated by $\mathrm{m}$ generators such that $g_{1}$ $=$ twice the $(n-m+1)-$ th row of an identity matrix of order and are the last rows of an identity matrix of order $n$ and $g_{2}, g_{3}, \ldots, g_{m}$ hence it follows that $(m-1)$ the loss of information on factor $\mathrm{F}_{\mathrm{n}-\mathrm{m}+1}$ due to confounding with blocks is given by

$\psi_{x}=\frac{2 \sum_{a_{n-m+1}} \ldots \sum_{a_{n}} w_{a_{1}, a_{2}, \ldots a_{n}} d_{a_{1}, a_{2}, \ldots, a_{n}} d_{a_{n-m+1}}^{*}}{(s-1)(s-1)^{2 m_{1}} s^{n+m-2 m_{1}}}$ 
using lemma 3.1 But if $\mathrm{a}=\mathrm{a}_{1} \mathrm{a}_{2} \ldots \mathrm{a}_{\mathrm{n}}$ is a treatment combination in the initial block, then

$a_{i}= \begin{cases}0, & \text { for } i=1,2, \ldots, n-m \\ a_{j}, & \text { for } i=n-m+1, n-m+2, \ldots ., n\end{cases}$

where $\mathrm{a}_{\mathrm{n}-\mathrm{m}+1}=0,2,4, \ldots, \mathrm{s}-2$ and $\mathrm{a}_{\mathrm{j}}=0,1,2, \ldots, \mathrm{s}-1$ for $j=n-m+2, n-m+3, \ldots, n$. Therefore for these deletion designs.

$$
\psi_{\mathrm{x}}=\frac{2 \mathrm{~s}^{\mathrm{n}-\mathrm{m}} \sum_{\mathrm{a}_{\mathrm{n}-\mathrm{n}+1}} \ldots \sum_{\mathrm{a}_{\mathrm{s}}} \mathrm{w}_{00} \ldots . \mathrm{a}_{\mathrm{n}-\mathrm{m}+1} \ldots \mathrm{a}_{\mathrm{n}} \mathrm{d}_{\mathrm{a}-\mathrm{n}-\mathrm{m}+2} \ldots \mathrm{a}_{\mathrm{n}} \mathrm{d}_{\mathrm{a}_{\mathrm{n}-\mathrm{m}+1}^{*}}^{*}}{(\mathrm{~s}-1)(\mathrm{s}-1)^{2 \mathrm{~m}_{\mathrm{t}}} \mathrm{s}^{\mathrm{n}+\mathrm{m}-2 \mathrm{~m}_{\mathrm{t}}}}
$$

It can be shown that

$\mathrm{d}_{\mathrm{a}_{\mathrm{j}}}= \begin{cases}\mathrm{s}-1, & \text { if } \mathrm{a}_{\mathrm{j}}=0 \text { and } \mathrm{l}=1,2, \ldots ., \mathrm{s}-1 \\ \mathrm{~s}-2, & \text { if } \mathrm{a}_{\mathrm{j}} \neq 0 \text { and } \mathrm{l}=1\end{cases}$

and

$d_{a_{n-m+1}}^{*}=\left\{\begin{array}{l}s(S-1), \text { if } a_{n-m+1}=0 \\ -s, \text { if } a_{n-m+1} \neq 0\end{array}\right.$

The following result on loss of information follow.

Theorem 4: Loss of information on the main effect of factor $\mathrm{F}_{\mathrm{n}-\mathrm{m}+1}$ or any two factor interactions of the form $\mathrm{F}_{\mathrm{j}} \mathrm{F}_{\mathrm{n}-\mathrm{m}+1}, \mathrm{j}=1,2, \ldots . ., \mathrm{n}-\mathrm{m}$ due to confounding with blocks, provided

$l=1$, is given by

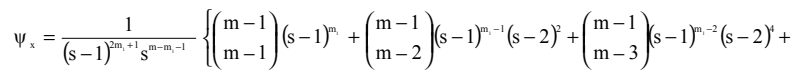

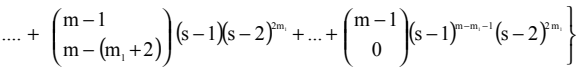

Example Consider a $4^{4}$ generalised cyclic design generated by $g_{1}=\begin{array}{llllll}0 & 2 & 0 & 0\end{array} \mathrm{~g}_{2}=\begin{array}{lllll}0 & 0 & 1 & 0\end{array}$ and $\mathrm{g}_{3}=\begin{array}{llll}0 & 0 & 0 & 1\end{array}$. Thus we have $b_{p}=8$ blocks of size $k_{p}=2 \times 4^{3}$. It follows by Theorem 2 that the main effect of factor $F_{1}$ is totally confounded with blocks while the main effect of factor $F_{2}$ and the two factor interaction $F_{1} F_{2}$ are partially confounded with blocks. All the other main effects and interaction are fully estimable. Loss of information on main effects of factor $F_{2}$ or on two factor interactions $\mathrm{F}_{1} \mathrm{~F}_{2}$ is given by $\psi_{\mathrm{x}}=1 /(\mathrm{s}-1)=0.33$

For the deletion designs of the form $4^{4-\mathrm{m}_{1}}(4-1)^{\mathrm{m}_{1}}, \quad \mathrm{~m}_{1}=1,2$, the main effects of factor $\mathrm{F}_{2}$ and the two factor interaction $\mathrm{F}_{1} \mathrm{~F}_{2}$ remain partially confounded using Theorem 3 . All other main effects and intersections are fully estimable.

The loss of information on the main effect of factor or on the two factor interaction $\mathrm{F}_{1} \mathrm{~F}_{2}$ is now as follows;

(i) For the $4^{3} \times 3$ deletion design

$\psi_{\mathrm{x}}=\frac{1}{(4-1)^{3} 4}\left\{\left(\begin{array}{l}3-1 \\ 3-1\end{array}\right)(4-1)+\left(\begin{array}{l}3-1 \\ 3-2\end{array}\right)(4-2)^{2}+\left(\begin{array}{c}3-1 \\ 0\end{array}\right) 3 \times 2^{2}\right\}=0.213$

(ii) For the $4^{2} \times 3^{2}$ deletion design $\psi_{\mathrm{x}}=0.201$

Note that for a $4^{6}$ generalised cyclic design generated by

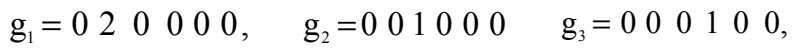
$\mathrm{g}_{4}=0000010$ and $\mathrm{g}_{5}=00000001$. Thus $\mathrm{k}_{\mathrm{p}}=2 \times 4^{4}$ and $\mathrm{b}_{\mathrm{p}}=8$. The same effects that were not estimable in the $4^{4}$ generalised cyclic design are still not estimable in this design and are the only ones. Loss of information on $\mathrm{F}_{2}$ or the two factor interaction $\mathrm{F}_{1} \mathrm{~F}_{2}$ remain the same. However

(i) For the $4^{5} \times 3$ deletion design $\psi_{x}=0.198$

(ii) For the deletion design $\psi_{\mathrm{x}}=0.125$

(iii) For the $4^{3} \times 3^{3}$ deletion design $\psi_{\mathrm{x}}=0.103$

(iv) For the $4^{2} \times 3^{4}$ deletion design $\psi_{\mathrm{x}}=0.122$

\section{CONCLUDING REMARKS}

These deletion designs are sometimes more efficient than the preliminary generalized cyclic design they were derived from with respect to loss of information. For example for $l=1$ using Theorem 4 above

$\psi_{\mathrm{x}}<\frac{(\mathrm{s}-1)^{\mathrm{m}-1}}{(\mathrm{~s}-1)^{2 \mathrm{~m}+1} \mathrm{~s}^{\mathrm{m}-\mathrm{m}-1}}=\mathrm{s}^{-(\mathrm{m}+1)}<(\mathrm{s}-1)^{-1}$

For some deletion designs the effects that were nonestimable in the preliminary generalized cyclic design are the same effects that are non-estimable in the resulting deletion designs as is the case in the above example. Lastly 
the deletion designs are more economical than the preliminary generalised cyclic design they are derived from because they require a smaller number of treatment combinations thus smaller number of experimental units.

\section{REFERENCES}

Bose, R.C.(1947): Mathematical theory of symmetrical factorial design. Sankya,8,107-166.

Chauhan,C.K(1989) : Construction of efficient single replicate designs .Preprint.

Dean,A.M (1978) : The analysis of interactions in single replicate generalized cyclic Designs. Journal of the Royal Statistical Society,ser.B.40,70-89.
Gachii,K.M (1993) : On the construction of deletion designs.Ph.D. thesis,University of Nairobi.

Gachii K.M and Odhiambo J.W (1997): Asymetrical single replicate designs, South African Statistical Journal,(1998) Vol 32,1-18.

John J.A and Dean A.M (1975) : Single replicate factorial experiments in generalized cyclic Designs: I Symmetrical arrangements, Journal of the Royal Statistical Society, ser.B. 37, 63-71.

Voss, D.T(1986) : First order deletion designs and the construction of efficient nearly Orthogonal factorial designs in small blocks, Journal of the American Statistical Association , 81,813-818. 